\title{
NEONATAL SEPSIS- TRENDS IN A PERIPHERAL TERTIARY HEALTH CARE FACILITY OF EASTERN INDIA
}

\author{
Purba Mukherjee1, Prativa Biswas'2, Sanghamitra Satpathi', Partha Sarathi Satpathi ${ }^{4}$
}

${ }_{1}^{1}$ Assistant Professor, Department of Microbiology, National Medical College, Kolkata, West Bengal, India.

${ }^{2}$ Assistant Professor, Department of Paediatrics, RG Kar Medical College, Kolkata, West Bengal, India.

3Joint Director (Medical and Health Services), Department of Pathology, Ispat General Hospital, Rourkela, Odisha, India.

4 Professor, Department of Microbiology, Midnapore Medical College and Hospital, Midnapore, West Bengal, India.

\begin{tabular}{l}
\hline ABSTRACT \\
BACKGROUND \\
There are many etiological agents of neonatal sepsis which differs from region to region and also from time to time in the same \\
place. Early diagnosis and appropriate therapy of septicaemia is of utmost importance to prevent the morbidity and mortality. The \\
present study is undertaken to determine the incidence of neonatal sepsis, its microbial profile, pattern of antibiotic susceptibility \\
of the bacterial isolate and also to evaluate the empirical antibacterial treatment used in a peripheral tertiary health care hospital.
\end{tabular}

\section{METHODS}

185 clinically suspected patients of neonatal sepsis in the age group of 0-28 days were included in the study. Blood culture and antibacterial sensitivity of all the isolates was done for all cases.

\section{RESULTS}

Out of 185, 51 (27.5\%) were early onset sepsis (EOS) and $134(72.4 \%)$ were late onset sepsis (LOS) with a male preponderance. In both EOS and LOS groups, significant culture positivity was observed $(\mathrm{p}<0.01)$. Respiratory distress was the most observed clinical presentation. Gram positive bacteria were responsible in 55 (44.3\%), Gram negative bacteria 51 (41.1\%) and Candida spp. in 18 $(14.5 \%)$ cases. Both Gram positive and Gram negative bacteria showed maximum resistance to Cephalosporins. Imipenem was also resistant in $15.7 \%$ Gram negative isolates. Regarding resistant pattern of the Candida spp., highest resistance was observed for Itraconazole.

\section{CONCLUSIONS}

The preponderance of LOS is also an important finding which can be minimized by adopting preventive measures by health care workers in periphery.

HOW TO CITE THIS ARTICLE: Mukherjee P, Biswas P, Satpathi S, et al. Neonatal sepsis- trends in a peripheral tertiary health care facility of eastern India. J. Evolution Med. Dent. Sci. 2019;8(14):1089-1093, DOI: 10.14260/jemds/2019/241

\section{BACKGROUND}

Neonatal sepsis is defined as a clinical syndrome characterized by systemic signs of infection in an infant of 28 days or younger and accompanied by isolation of bacterial pathogen from the blood stream.1,2 In the settings where microbiological confirmation is difficult, diagnosis of neonatal sepsis may be presumed in the presence of clinical signs and supportive laboratory investigations that in the clinicians' judgement warrant at least a week of anti-bacterial therapy. Based on the timing of clinical presentation, neonatal sepsis is often differentiated into early onset sepsis (EOS) and late onset sepsis (LOS). EOS is defined as any infection presenting in the first 72 hours of life, whereas LOS occurs after 72 hours of postnatal life. ${ }^{1}$ Globally sepsis is still one of the major causes of morbidity and mortality in neonates, in spite of recent advances in health care units. ${ }^{3}$

'Financial or Other Competing Interest': None.

Submission 04-01-2019, Peer Review 22-03-2019,

Acceptance 29-03-2019, Published 08-04-2019.

Corresponding Author:

Dr. Partha Sarathi Satpathi,

Professor,

Department of Microbiology,

Midnapore Medical College and Hospital,

Midnapore, Dt; West Midnapore,

West Bengal, India.

E-mail: pssatpathi@gmail.com

DOI: $10.14260 /$ jemds $/ 2019 / 241$
Neonatal mortality is one of the indicators for the measurement of states of health of a nation. Neonatal septicaemia is responsible for approximately $25 \%$ of neonatal death in the world and most of these are in the developing countries. ${ }^{4}$ As per the record of national neonatal perinatal database (NNPD) 2002-2003, the incidence of neonatal septicaemia has been reported to be 30/1000 lives birth in India. ${ }^{5}$ There are 3.1 million newborn death every year occurring mainly in low income countries and out of them about 1 million are caused by infections such as neonatal sepsis, meningitis and pneumonia.6,7

Common microorganisms causing neonatal sepsis are gram positive and gram-negative bacteria along with some fungi and viruses. ${ }^{1}$ There is a considerable variation of the aetiological agent of neonatal sepsis which differs from region to region and also from time to time in the same place. This is due to changing pattern of antibiotics and changes in life styles.8,9 Early diagnosis and appropriate therapy of septicaemia is of utmost importance to prevent the morbidity and mortality. ${ }^{10}$ With this background in mind we undertook the present study to determine the incidence of neonatal sepsis, its microbial profile, pattern of antibiotic susceptibility of the bacterial isolate and to evaluate the empirical antibacterial treatment used in this peripheral tertiary health care facility of South Bengal catering the rural population of four adjoining districts. 


\section{METHODS}

The study was carried out in the department of Microbiology in collaboration with Paediatric department of Midnapore Medical College and hospital from Nov, 2016 to Dec, 2017 after the clearance of the Institutional Ethical Committee.

I. Study Design: A prospective hospital based cross sectional observational study conducted on the neonates with clinical signs of sepsis admitted to the SNCU and Paediatric wards of a tertiary care hospital.

II. Study Populations: A total of 185 clinically suspected patients of neonatal sepsis in the age group 0-28 days were included in the study.

\section{Inclusion Criteria}

The patients having the following clinical presentation were suspected to be suffering from neonatal sepsis.

a) Decreased activity, not sucking at all, lethargy, excessive stiffness along with concerned on the part of the nurse or mother that the patient is not right.

b) Hypothermia or Hyperthermia $\left(<36.4{ }^{\circ} \mathrm{c}\right.$ or $\left.>37.5^{\circ} \mathrm{c}\right)$.

c) Respiratory rate $>60$ breaths per minutes or apnoea.

d) Tachycardia, Bradycardia, hypotension or shock.

e) Feeding intolerance, vomiting, jaundice, signs of necrotizing enterocolitis.

f) Bulging fontanels, neck retraction, shrill cry \& seizures.

g) Redness of the umbilicus extending to the surroundings skin.

h) Focal signs of infections e.g. abscess, ophthalmitis, mastoiditis etc. ${ }^{1,11}$

\section{Laboratory Procedures}

A single sample of blood was collected from a peripheral vein. The local site was cleansed by $70 \%$ alcohol, $1 \%$ povidone iodine followed by $70 \%$ alcohol again. One $\mathrm{ml}$ of blood was collected and inoculated into brain heart infusion broth in 1:10 ratio and the blood culture bottle were sent to Microbiology Laboratory. It was incubated for 7 days at $37{ }^{\circ} \mathrm{C}$ in aerobic condition and in carbon dioxide extinction jar. Subculture from BHI broth in sheep blood agar, chocolate agar, MacConkey's agar, was done on $2^{\text {nd }}, 4^{\text {th }}$ and $7^{\text {th }}$ day. Isolate on the respective media were subjected to gram staining and the isolate were identified as per standard microbiological techniques. ${ }^{12}$

Antibacterial sensitivity of all the isolates ware performed on Muller- Hinton agar plates by Kirby Bauer disc diffusion method as per clinical laboratory standard institute

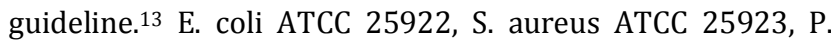
aeruginosa ATCC 27853 were used as standard strains.

\section{Drug Used in Disc Diffusion}

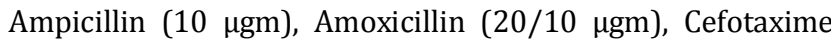
(30 $\mu \mathrm{gm})$, Cefuroxime $(30 \mu \mathrm{gm})$, Ceftriaxone $(30 \mu \mathrm{gm})$, Ciprofloxacin (5 $\mu \mathrm{gm})$, Levofloxacin (5 $\mu \mathrm{gm})$, Erythromycin (5

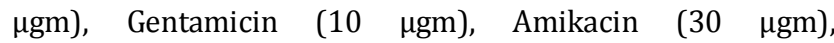
Azithromycin (15 $\mu \mathrm{gm})$, Vancomycin (30 $\mu \mathrm{gm})$, Imipenem (10 $\mu \mathrm{gm})$, Cephalotoxin (30 $\mu \mathrm{gm})$, Netilmicin $(30 \mu \mathrm{gm})$.The drugs were obtained from HiMedia Laboratories.

\section{Statistical Analysis}

Statistical analysis was done using Chi-square and T-test (Two-sample independent T-test) in the Open Epi version 3.01(https://www.openepi.com/Menu/OE_Menu.htm). The level of significance for the test was set as $\mathrm{P}<0.05$.

\section{RESULTS}

\begin{tabular}{|c|c|c|c|c|c|c|c|c|}
\hline Sex & \multicolumn{2}{|c|}{ EOS } & $\begin{array}{c}\text { P } \\
\text { value }\end{array}$ & \multicolumn{2}{c|}{ LOS } & $\begin{array}{c}\text { P } \\
\text { value }\end{array}$ \\
\hline & Clinical & $\begin{array}{c}\text { Culture } \\
\text { Positive }\end{array}$ & & Clinical & \multicolumn{2}{c|}{$\begin{array}{c}\text { Culture } \\
\text { Positive }\end{array}$} & \\
\hline & & & $\mathbf{\%}$ & & & & $\mathbf{\%}$ & \\
\hline Male & 31 & 21 & $67.7 \%$ & & 83 & 59 & $71.08 \%$ & \\
\hline Female & 20 & 12 & $60 \%$ & & 51 & 32 & $62.7 \%$ & \\
\hline Total & $\begin{array}{c}\mathbf{5 1} \\
(\mathbf{2 7 . 5 \% )})\end{array}$ & $\mathbf{3 3}$ & $\mathbf{6 4 . 7 \%}$ & $\mathbf{0 . 0 1}$ & $\begin{array}{c}\mathbf{1 3 4} \\
\mathbf{( 7 2 . 4 )}\end{array}$ & $\mathbf{9 1}$ & $\mathbf{6 7 . 9 \%}$ & $\mathbf{0 . 0 1}$ \\
\hline
\end{tabular}

Table 1. Sex Wise Distribution of Clinically Suspected and Culture Positive Septicaemia in E.O.S. and L.O.S. Group

\begin{tabular}{|c|c|c|c|c|}
\hline Clinical Presentation & EOS & $\%$ & LOS & $\%$ \\
\hline 1.Resp. Distress & 15 & $29.4 \%$ & 31 & $23.1 \%$ \\
\hline 2.Hypo. or Hyperthermia & 11 & $21.5 \%$ & 21 & $15.6 \%$ \\
\hline 3. Jaundice & 1 & $1.9 \%$ & 7 & $13.72 \%$ \\
\hline 4. Seizure & 3 & $5.8 \%$ & 5 & $3.7 \%$ \\
\hline $\begin{array}{l}\text { 5. Hypotension or } \\
\text { Tachycardia, Brachycardia }\end{array}$ & 4 & $7.8 \%$ & 7 & $5.2 \%$ \\
\hline 6. Reduced Activity & 9 & $17.6 \%$ & 31 & $23.1 \%$ \\
\hline 7. Feeding Intolerance & 5 & $9.8 \%$ & 29 & $21.6 \%$ \\
\hline $\begin{array}{l}\text { 8. Redness of Umbilicus } \\
\text { Extending to Skin }\end{array}$ & 3 & $5.8 \%$ & 3 & $2.2 \%$ \\
\hline \begin{tabular}{|c|} 
Total \\
\end{tabular} & 51 & $100 \%$ & 134 & $100 \%$ \\
\hline \multicolumn{5}{|c|}{ Table 2. Clinical Presentation of Neonatal Septicaemia } \\
\hline \multicolumn{5}{|c|}{ P value -0.04} \\
\hline
\end{tabular}

\begin{tabular}{|c|c|c|c|c|c|}
\hline Pathogen & Frequency & EOS & $\mathbf{\%}$ & LOS & $\mathbf{\%}$ \\
\hline 1. Staph (+) & $33(27.2 \%)$ & 10 & $30.30 \%$ & 23 & $69.69 \%$ \\
\hline 2. Staph (-) & $14(11.2 \%)$ & 5 & $35.71 \%$ & 9 & $64.28 \%$ \\
\hline 3. Kleb & $18(14.5 \%)$ & 7 & $38.88 \%$ & 11 & $61.11 \%$ \\
\hline 4. Enterococcus & $08(6.4 \%)$ & 3 & $37.5 \%$ & 5 & $62.50 \%$ \\
\hline 5. E. coli & $10(8.06 \%)$ & 1 & $10 \%$ & 9 & $90 \%$ \\
\hline 6. Acinetobacter & $02(1.6 \%)$ & 1 & $50 \%$ & 1 & $50 \%$ \\
\hline 7. Citrobacter & $07(5.6 \%)$ & 1 & $14.28 \%$ & 1 & $14.28 \%$ \\
\hline 8. Candida & $18(14.5 \%)$ & 5 & $27.77 \%$ & 13 & $72.22 \%$ \\
\hline 9. Proteus & $09(7.2 \%)$ & 0 & $0 \%$ & 9 & $100 \%$ \\
\hline 10. Pseudomonas & $05(4.05 \%)$ & 0 & $0 \%$ & 5 & $100 \%$ \\
\hline Total & $\mathbf{1 2 4}$ & $\mathbf{3 3}$ & $\mathbf{2 6 . 6 1 \%}$ & $\mathbf{9 1}$ & $\mathbf{7 3 . 3 8 \%}$ \\
\hline
\end{tabular}

Table 3. Common Isolated Pathogen in Different Groups $P$ value -0.04

\begin{tabular}{|c|c|c|c|c|c|c|c|c|c|c|c|}
\hline Gm (+) & & CXM & CTX & AMC & OF & SC & AK & AZM & Va & Le & G \\
\hline Staph (+) & 33 & 32 & 32 & 24 & 16 & 20 & 3 & 31 & S & 5 & 8 \\
\hline Staph (-) & 14 & 9 & 8 & 8 & 5 & 7 & 2 & 11 & S & 5 & 5 \\
\hline Enterococcus & 8 & 5 & 6 & 3 & 3 & 4 & 0 & 6 & S & 2 & 3 \\
\hline Total & $\mathbf{5 5}$ & $\mathbf{4 6}$ & $\mathbf{4 6}$ & $\mathbf{3 5}$ & $\mathbf{2 4}$ & $\mathbf{3 1}$ & $\mathbf{5}$ & $\mathbf{4 8}$ & & $\mathbf{1 2}$ & $\mathbf{1 6}$ \\
\hline Percentage & & $83.6 \%$ & $83.6 \%$ & $63.6 \%$ & $43.6 \%$ & $56.3 \%$ & $9.09 \%$ & $87.27 \%$ & $21.8 \%$ & $29.09 \%$ \\
\hline \multicolumn{10}{|c|}{ Table 4. Resistance Pattern of Gram-Positive Organisms } \\
\hline
\end{tabular}




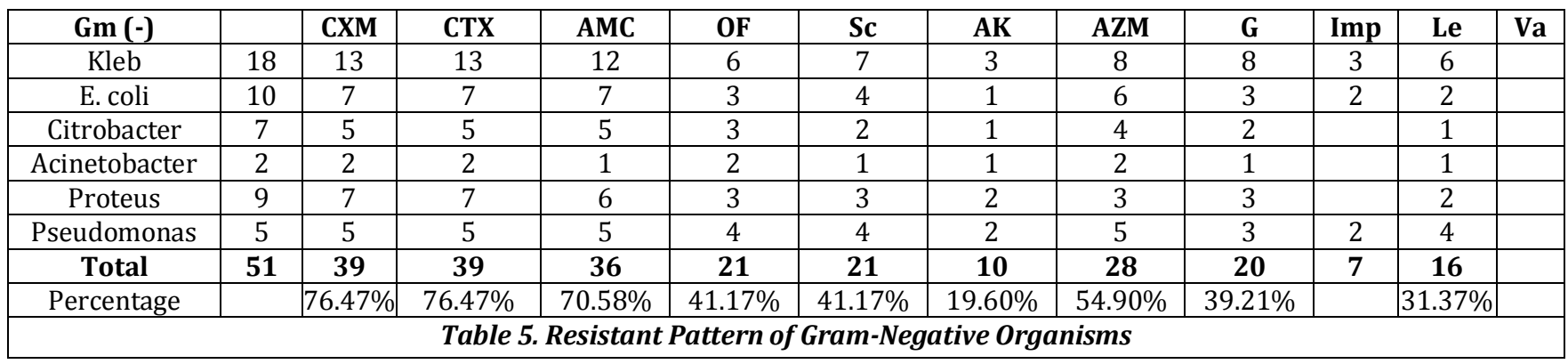

\begin{tabular}{|c|c|c|c|c|}
\hline Drugs & Ketoconazole & Fluconazole & Itraconazole & Voriconazole \\
\hline Candida sp. & $10(55.5 \%)$ & $8(44.4 \%)$ & $17(94.4 \%)$ & $8(44.4)$ \\
\hline \multicolumn{5}{|c|}{ Table 6. Resistant Pattern of Candida spp. } \\
\hline
\end{tabular}

In the study period we have included 185 clinically suspected cases of neonatal septicaemia and out of this 51 $(27.5 \%)$ were EOS and $134(72.4 \%)$ were LOS (Table 1). Altogether in the EOS and LOS group 114 (60.1\%) were males and 71 (38.3\%) were females. The overall rate of male to female ratio in clinical sepsis is 1.6:1. In both EOS and LOS group, both male and female had statistically significant culture positivity (Table-1). In the EOS group (Table 2) the most important clinical presentations were respiratory distress 15 (29.4\%), Hypothermia 11 (21.5\%) and reduced activity $9(17.6 \%)$. In the LOS group the major clinical presentations were respiratory distress 31 (23.1\%), reduced activity 31 (23.1\%), feeding intolerance 29 (21.6\%) and Hypothermia 21 (15.6\%). The average difference in clinical presentation in EOS and LOS group was statistically significant ( $\mathrm{p}$ value 0.04 ). Blood culture was positive in 124 $(67.02 \%)$ and amongst them 33 (26.6\%) were early onset sepsis and $91(73.3 \%)$ were late onset sepsis. The male to female ratio in culture positive sepsis was $1.8: 1$, where males were $70.1 \%$ and female were $61.9 \%$. Gram positive bacteria were responsible in 55 (44.3\%), Gram negative bacteria 51 (41.1\%) and Candida sp in 18 (14.5\%) cases. Coagulase positive Staphylococcus was the commonest pathogen $(27.2$ $\%)$ followed by Klebsiella sp. (14.5\%) and Candida sp (14.5 $\%)$, (Table 3). Other common pathogens isolated were coagulase negative staphylococcus in 14 (11.2\%), E.coli (8.06 \%), Proteus 9 (7.2\%), Citrobacter 7(5.6\%), Pseudomonas 5 (4.05\%), Enterococcus 8 (6.4\%) and Acinetobacter 2 (1.6\%). Coagulase positive Staphylococcus was the commonest pathogen in EOS group 10 (30.3\%) followed by Klebsiella $(21.2 \%)$ and Candida sp. (15.1\%). In the LOS group also commonest pathogen was coagulase positive Staphylococcus 23(25.2\%) followed by Candida sp. 13 (14.2\%) and Klebsiella sp. $11(12.1 \%)$. The difference in prevalence of pathogens in both EOS and LOS were statistically significant ( $p$ value 0.04 ).

Antibacterial and antifungal sensitivity performed for all isolates (Table 4, 5, 6). Gram positive cocci were showing resistance ranging from $9 \%$ to $87 \%$. Most resistant antibacterials were AZM 87.2\%, CXM and CTX 83.6\% each, AMC $63.6 \%$ and Sparfloxacin 56.3\%. Vancomycin was sensitive to all of them. Amongst the positive cocci Staphylococcus showed maximum resistance to Cephalosporins (96.9\%) followed by AZM (93.9\%) and AMC (72.7\%).The Gram-negative bacilli showed resistance ranging from $15.7 \%$ to $76.5 \%$. Most resistant antibacterials were Cephalosporins $76.5 \%$ followed by AMC $70.6 \%$ and AZM $58.8 \%$. Imipenem was also resistant in $15.7 \%$ Gram negative isolates. Amongst the gram-negative bacilli Klebsiella was $72.2 \%$ resistant to Cephalosporins followed by AMC 66.6\%, Gentamycin and AZM 44.4\% each and Imipenem 16.7\%. Pseudomonas was $100 \%$ resistant to Cephalosporins, AMC and AZM. It was resistant to Imipenem in $40 \%$ cases. Regarding resistant pattern of the Candida $\mathrm{sp}$, it was observed that highest resistance was in Itraconazole (94.4\%) followed by ketoconazole (55.5\%), Fluconazole and Voriconazole $44.4 \%$ each.

\section{DISCUSSION}

Sepsis still remains an important factor for the death of neonates globally and contributes for the major concern in the morbidity and mortality in this age group. More than $40 \%$ under 5 deaths globally occur in the neonatal period, resulting in 3.1 million newborn deaths every year. ${ }^{3,5}$ As there is dearth of proper laboratory support, the aetiological factors of sepsis particularly bacterial and fungal causes could not be discerned. The problem is more complicated by the non-specific clinical signs and symptoms of neonatal sepsis. So early diagnosis and treatment needs identification of the causative agents and the report of sensitivity of the antibacterials and antifungals, on the basis of which an empirical and definitive treatment policy can be adopted by the clinicians. Knowledge of sensitivity pattern of the antibacterial and antifungal will lead to establishment of a proper policy in the area leading to prevention of mortality and morbidity in neonatal sepsis cases. Regular survey of sepsis cases can identify the management and preventive initiations required for different geographical areas in different time.

In this study, the most common presentation of clinical neonatal sepsis was respiratory distress (24.8\%) followed by reduced activity (21.6\%), feeding intolerance $(21.08 \%)$ and hypo or hyperthermia $(17.3 \%)$. In the EOS group most common \& least common presentations were respectively respiratory distress $(29.4 \%)$ and jaundice $(1.9 \%)$, whereas in LOS group it was respiratory distress $(23.1 \%)$ and redness of umbilicus extending to skin $(2.23 \%)$ respectively. Respiratory distress was also shown to be the commonest clinical presentation reported by Sasaram et al 14 in south India.

Out of the 185 clinically suspected neonatal sepsis cases in this study, $124(67.02 \%)$ were proved to be actually suffering from culture positive sepsis. Our findings are a bit higher in comparison to some other studies from India which ranges from $19 \%$ to $52.6 \% .{ }^{11,14-17}$ The higher rate might be 
due to overcrowding in the neonatal setup, transmission of organism from health care workers due to lack of knowledge of different infection control measures and also lack of hygiene in mothers of the newborn. Amongst the culture positive sepsis cases, 33(64.7\%) were EOS and 91 (67.9\%) LOS. Various reports from India and abroad had more EOS than LOS.14-16,18

In our study LOS (73.3\%) were more than EOS (26.6\%) which is in agreement with report of Emam et al ${ }^{19}$ ( LOS, $47.4 \%>$ EOS, $32.2 \%$ ). The major factor for LOS might be due to non-effective hand washing, inadequate knowledge of infection control measures and nasal carriage of health care worker. ${ }^{20}$ There is a male preponderance in neonatal sepsis cases $(1: 6: 1)$ in our study which is similar to report from other studies.8,14,18

The aetiological agents of neonatal septicaemia differ in different geographical locations throughout the world and changes from time to time in these geographical areas. Accordingly there is a shift of identity of these agents from predominant Gram negative bacteria to Gram positive bacteria. ${ }^{11}$ This diverse aetiology might be due to changes in the uses of antibacterial and lifestyle in varying geographical area. ${ }^{19}$ Our study found predominance of gram positive cocci in septicaemia (44.3\%) followed by gram negative bacilli $(41.1 \%)$ and Candida sp. (14.5\%). This observation is in agreement with other reports. ${ }^{11}$ In contrast to that, some other studies have reported higher prevalence of gram negative bacilli instead of gram positive cocci. ${ }^{21-23}$ In neonatal septicaemia Candida as a causative agent has been reported by Jothi et al ${ }^{15}$ and Eman et al. ${ }^{19}$ Similarly $14.5 \%$ of our cases were due to Candida. Transmission from health care workers due to lack of personal hygiene might be an important factor for isolation of Candida in our study. Varadker et al 24 isolated $19.4 \%$ Candida from neonatal sepsis. Coagulase positive Staphylococcus was the commonest amongst the grampositive cocci, and Klebsiella in gram negative bacilli group. In comparison to the E.O.S group (30.3\%), the L.O.S group had more Gram-negative septicaemia (45.05\%).

Antibiotic resistance is a global problem at present. In developing countries multidrug resistance in neonatal sepsis is increasing due to easy availability, lack of proper antibiotic policy and inappropriate use of broad spectrum antibacterial.15 In our study Gram positive cocci showed highest resistance to Azithromycin (87.2\%) followed by Cefotaxime, Cefuroxime and Amoxiclav at $83.6 \%, 83.6 \%$ and $63.6 \%$ respectively. Minimum resistance was shown to Amikacin (9.09\%) and all Gram-positive cocci isolated in our study showed sensitivity to Vancomycin. Amongst the Grampositive cocci, coagulase positive Staphylococcus showed highest resistance to both Cefotaxime and Cefuroxime $(96.9 \%$ each) followed by Azithromycin (93.9\%) and Amoxiclav (72.7\%). Similar report of resistance of gram-positive cocci was found in other studies. ${ }^{11,15,19}$

In the Gram-negative bacilli group maximum resistance was shown to Cefotaxime (76.5\%), Cefuroxime (76.5\%) and Amoxiclav (70.6\%). Though minimum resistance was shown to Amikacin (19.6\%), Gram negative bacilli also showed resistance to Imipenem (15.7\%). Amongst the Gram-negative bacilli, Pseudomonas was $100 \%$ resistant to CTX, CXM, AMC and AZM. It also showed a higher resistance to Amikacin and Imipenem (40\% each). In comparison Klebsiella, the most common Gram-negative isolate, showed lower resistance to
Cephalosporin, AMC (72.2\% and 66.6\%) and Imipenem (16.7\%). The resistance pattern showed by the Gramnegative bacilli are also reported by other studies.11,15,20,25

The Candida isolates from the neonatal septicaemia cases showed highest resistance to Itraconazole (94.4\%) in comparison to ketoconazole (55.4\%) and Fluconazole $(44.4 \%)$.

\section{CONCLUSIONS}

High level of culture positive neonatal sepsis is of great concern in tertiary health care set up. The preponderance of L.O.S. is also an important finding which can be minimized by adopting preventive measures by health care workers and other care givers. Though many other studies have predominant Gram-negative sepsis, we observed predominance of Gram-positive sepsis.

\section{ACKNOWLEDGEMENTS}

We acknowledge Mr. Debashis Roy, Medical Laboratory Technologist for helping in the laboratory work of this study.

\section{REFERENCES}

[1] Suresh G, McKenney WV. Neonatal sepsis. In: Bhandari $\mathrm{V}$, edr. Manual of Neonatology. $1^{\text {st }}$ edn. Delhi, India: Jaypee Brothers Publishers and Distributors Pvt. Ltd., 2008: p. 346-56.

[2] Edwards MS, Baker CI. Sepsis in the newborn. In: Gershon AA, Hotez RJ, Katz SL, eds. Krugman's Infectious diseases of children. Philadelphia, PA, USA: Mosby 2004: p. 545.

[3] Wu JH, Chen CY, Tsao PN, et al. Neonatal sepsis: a 6year analysis in a neonatal care unit in Taiwan. Pediatrics and Neonatology 2009;50(3):88-95.

[4] WHO Newborns: Reducing Mortality. http://www.who.int/mediacentre/factsheets/fs333/e n/. [Last cited on 2013 May 25]

[5] Report of the National Neonatal Perinatal Database. Report 2002-2003. NNPD Network. [Last accessed on 2010 July 17] http:// www.newbornwhocc.org/pdf/nnpd_report_200203.PDF

[6] UNICFF, WHO, the World Bank, and the United Nations, Levels and Trends in Child Mortality, UNICEF, New York, NY, USA, 2011.

[7] Black RF, Cousens S, Johnson HI, et al. Global, regional and national causes of child mortality in 2008: a systemic analysis. The Lancet 2010;375(9730):196987.

[8] Shrestha S, Adhikari N, Rai BK, et al. Antibiotic resistance pattern of bacterial isolates in neonatal care unit. Journal of the Nepal Medical Association 2010;50(4):277-81.

[9] Klein JO, Remington JS. Current concepts of infection of the fetus and newborn infant. In: Remington JS, Klein JO, eds. Infectious diseases of the fetus and newborn. Philadelphia, Pa, USA: WB Saunders 2000: $p$. $1-24$.

[10] Levy I, Leibovici L, Ducker M, et al. A prospective study of Gram-negative bacteraemia in children. Pediatr Infect Dis J 1996;15(2):117-22. 
[11] Thakur S, Thakur K, Sood A, et al. Bactteriological profile and antibiotic sensitivity pattern of neonatal septicaemia in a rural tertiary care hospital in North India. Indian Journal of Medical Microbiology 2016;34(I):67-71.

[12] Collee JG, Marr W. Culture of Bacteria. In: Collee JG, Fraser AG, Marmion BP, et al. eds. Mackie and McCartney Practical Medical Microbiology. 14th edn. New York: Churchill Livingstone 1996: p. 113-29.

[13] Clinical and Laboratory Standards Institute. Performance Standards for Antimicrobial Susceptibility Testing, Twenty-first Informational Supplement M100-S21. Wayne, PA: CLSI: 2011.

[14] Sarasam SE, Geetha S, Kumar SS. Clinical and epidemiological profile of neonatal sepsis in referral care NICU in South Kerala. Journal of Medical Science and Clinical Research 2017;5(3):19329-33.

[15] Jyothi P, Basavaraj MC, Basavaraj PV. Bacteriological profile of neonatal septicaemia and antibiotic susceptibility pattern of the isolates. Journal of Natural Science, Biology and Medicine 2013;4(2):306-9.

[16] Muley VA, Ghadage DP, Bhore AV. Bacteriological profile of neonatal septicemia in a tertiary care hospital from Western India. J Glob Infect Dis 2015;7(2):75-7.

[17] Murty DS, Gyaneshwari M. Blood cultures in pediatric patients: a study of clinical impact. Indian J Med Microbiol 2007;25(3):220-4.

[18] Al-Shamahy HA, Sabrah AA, Al-Robasi AB, et al. Types of bacteria associated with neonatal sepsis in AlThawra University Hospital, Sana'a Yemen and their antimicrobial profile. Sultan Qaboos University Medical Journal 2012;12(1):48-54.
[19] El-Din RSEM, Adel El-Sokkary MM, Bassiouny MR, et al. Epidemiology of neonatal sepsis and implicated pathogens: a study from Egypt. Article ID 509484, BioMed Research International 2015;2015: p. 11.

[20] Satpathi PS, Maity AB, Mukherjee P, et al. Nasal carriage of staphylococcus aureus and the quantum of their methicillin resistance amongst the health care workers in a peripheral tertiary care centre of Eastern India. Journal of Evolution of Medical and Dental Sciences 2015;4(90):15537-42.

[21] Agnihotri N, Kaistha N, Gupta V. Antimicrobial susceptibility of isolates from neonatal septicaemia. Jpn J Infect Dis 2004;57(6):273-5.

[22] Sundaram V, Kumar P, Dutta S, et al. Blood culture confirmed bacterial sepsis in neonates in a North Indian tertiary care center: changes over the last decade. Jpn J Infect Dis 2009;62(1):46-50.

[23] Jaswal RS, Kaushal RK, Goel A, et al. Role of C-reative protein in deciding duration of antibiotic therapy in neonatal septicaemia. Indian Pediatr 2003;40(9):8803.

[24] Baradkar VP, Mathur M, Kumar S, et al. Candida glabrata: emerging pathogen in neonatal sepsis. Annals of Tropical Medicine and Public Health 2008;1(1):5-8.

[25] Bhat YR, lewis LE, Vandana KE. Bacterial isolates of early onset neonatal sepsis and their antibiotic susceptibility pattern between 1998 and 2004: an audit from a centre in India. Ital J Pediatr 2011;37:32. 